\title{
Symmetrical Giant Facial Plaque-Type Juvenile Xanthogranuloma: A Case Report with a Successful Response to Fractional $\mathrm{CO}_{2}$ Laser Treatment
}

\author{
Young In Lee, Sang Ho Oh \\ Department of Dermatology, Severance Hospital, Cutaneous Biology Research Institute, Yonsei University College of Medicine, Seoul, Korea
}

Symmetrical giant facial plaque-type juvenile xanthogranuloma (SGFP-JXG) is a rare variant of juvenile xanthogranuloma, reported only in two cases in the literature. We report a case of a 3-year-old Korean boy who developed bilateral yellowish indurated plaques on both cheeks since 1 year after birth. A skin biopsy revealed numerous foam cells and Touton type giant cells throughout the upper dermis, and its immunohistochemical studies resulted positive for CD68 and negative for S-100. The boy was therefore diagnosed as a persistent SGFP-JXG. As the lesion did not show any signs of spontaneous regression, we performed a single session of fractional ablative $\mathrm{CO}_{2}$ laser, which resulted in a significant reduction of the lesion. This is the first case report of a persistent SGFP-JXG on which a single ablative laser therapy was performed with a successful outcome. (Ann Dermatol 31(2) 209 212, 2019)

\section{-Keywords-}

Histiocytosis, Juvenile xanthogranuloma, Laser therpy, Xanthomatosis

Received November 28, 2017, Revised January 9, 2018, Accepted for publication March 14, 2018

Corresponding author: Sang Ho Oh, Department of Dermatology and Cutaneous Biology Research Institute, Yonsei University College of Medicine, 50-1 Yonsei-ro, Seodaemun-gu, Seoul 03722, Korea. Tel: 82-2-2228-2080, Fax: 82-2-393-9157, E-mail: ODDUNG93@yuhs.ac ORCID: https://orcid.org/0000-0002-4477-1400

This is an Open Access article distributed under the terms of the Creative Commons Attribution Non-Commercial License (http://creativecommons. org/licenses/by-nc/4.0) which permits unrestricted non-commercial use, distribution, and reproduction in any medium, provided the original work is properly cited.

Copyright (c) The Korean Dermatological Association and The Korean Society for Investigative Dermatology

\section{INTRODUCTION}

Symmetrical giant facial plaque-type juvenile xanthogranuloma (SGFP-JXG) is an uncommon type of xanthogranuloma, which was first described by Gunson et al. ${ }^{1}$ in 2008. Cutaneous manifestation of JXG typically presents as a solitary, well-separated yellow or red-brownish papule or nodule, measuring up to $1 \mathrm{~cm}$ in most cases $^{2}$. A large or diffuse plaque-type lesion as shown in this case is notably rare. Histologically, JXG consists of a well demarcated mixed infiltrates of mononuclear histiocytes with vacuolated cytoplasm and multinuclear giant cells, mostly Touton type giant cells, on a background of scattered lymphocytes, neutrophils, and mast cells ${ }^{3}$. Immunohistochemical staining confirms the diagnosis of JXG, with the histiocytes being stained in CD68. JXG is negative for protein S-100 and CD1a, therefore differentiating it from Langerhans cell histiocytosis ${ }^{4}$.

Plaque types of JXG at extrafacial sites have been occasionally reported in the literature ${ }^{2,5}$. SGFP-JXG, however, is reported only in two previous cases ${ }^{6}$. Herein, we report another rare case of SGFP-JXG on a 3-year-old boy, which persisted for 2 years without any signs of regression. This is the first case report of a SGFP-JXG on which a single fractional ablative laser therapy was performed with a promising outcome.

\section{CASE REPORT}

A 3-year-old Korean boy was referred to our clinic with bilateral yellowish indurated plaques on both cheeks since 1 year after birth (Fig. 1A). Physical examinations revealed no ophthalmic or mucosal involvements, and palpable lymph nodes were not observed. Laboratory findings including lipid profiles such as total cholesterol, triglyceride, 

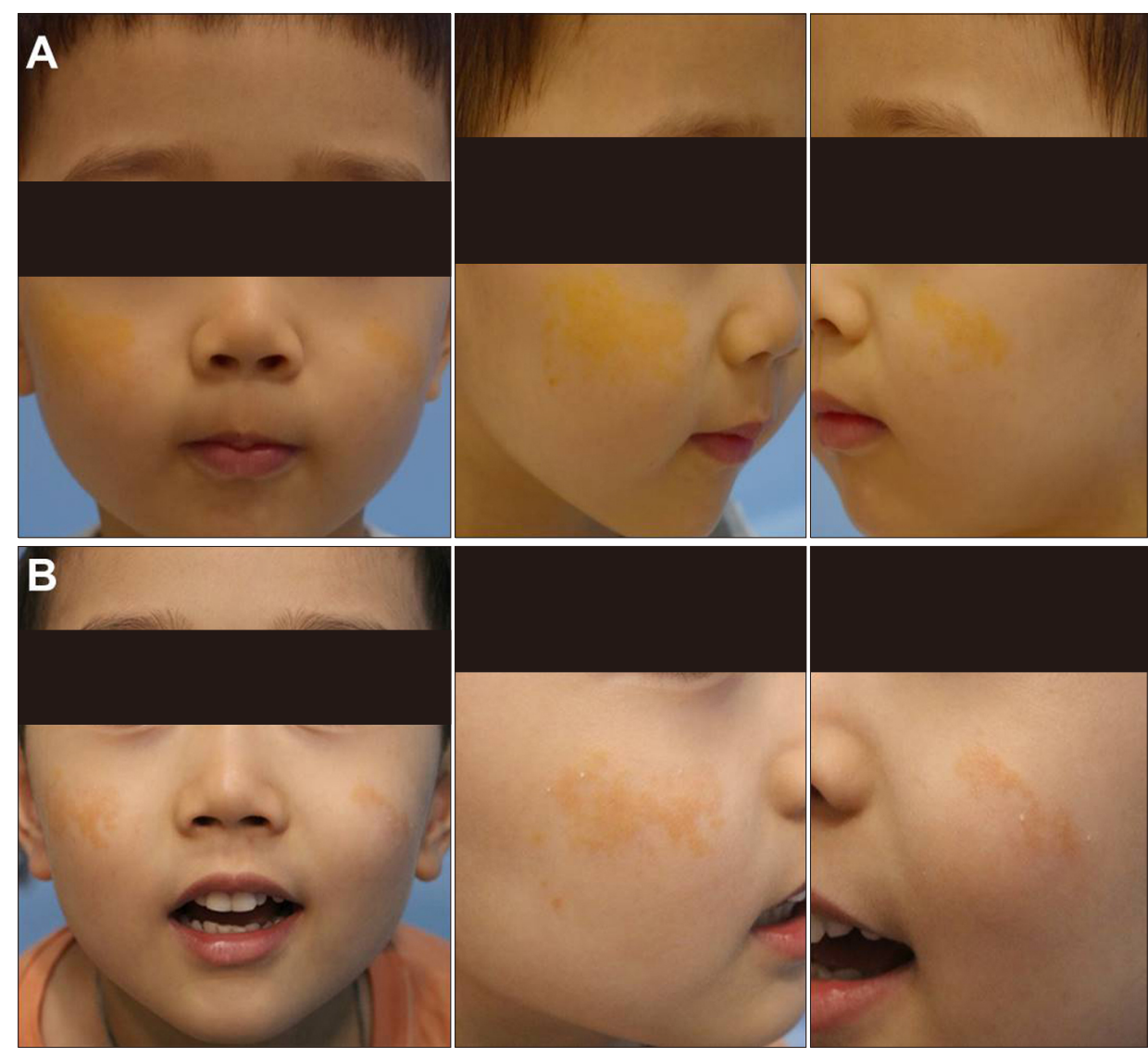

Fig. 1. We received the patient's consent form for publishing all photographic materials. (A) Initial photography of the bilateral symmetric yellowish plaques distributed on both cheeks. (B) Six-month follow-up photography after a single session of fractional ablative $\mathrm{CO}_{2}$ laser, showing reduced sizes of the lesions.

high density lipoprotein-, and low density lipoproteincholesterol were within normal limits. A skin biopsy was performed, and the histologic findings showed numerous foam cells with several Touton giant cells consisting of a lipid cytoplasm with a ring of nuclei, and occasional foreign body giant cells, throughout the upper dermis (Fig. 2A, B). The immunohistochemical staining result was positive for CD68 and negative for S-100 (Fig. 2C, D). Based on the clinicopathologic features, the patient was diagnosed as a SGFP-JXG. As the lesion did not show any signs of spontaneous regression, we performed a single session of fractional ablative $\mathrm{CO}_{2}$ laser, and a significant reduction of the size was observed throughout the next 6 months of follow-up period without signs of recurrence (Fig. 1B).

\section{DISCUSSION}

SGFP-JXG is reported in only two case studies since $2008^{1,6}$. In both cases, the lesions persisted for longer than 6 years, and had not shown a sign for spontaneous resolution. In one case, the 10-year-old patient simultaneously had JXG on the arms, and the extrafacial site disappeared spontaneously ${ }^{6}$. Furthermore, none of the cases observed internal organ involvements.
A confounding factor to our final diagnosis was its differential diagnosis with diffuse normolipemic plane xanthoma (DNPX). DNPX was first described by Altman and Winkelmann in 1962, and the features of this entity are: (a) xanthelasma palpebrarum, (b) diffuse plane xanthomas of the head, neck, trunk, or extremities, and (c) plasma lipid values that are within normal limits ${ }^{7,8}$. Its skin biopsy shows an accumulation of foam cells and Touton giant cells, along the infiltrated histiocytes that are CD68 positive, and CD1a and S-100 negative. DNPX is a rare xanthoma variant that has been associated with hematologic disorders, and only 45 cases are reported in the English literature between 1962 and 2013 ${ }^{9}$. Although histologically challenging to distinguish with JXG, DNPX typically shows characteristic xanthelasma appearing first in most cases, and tends to occur more frequently in adults ${ }^{8,10,11}$. Therefore, the clinical presentation of our case without preceding appearance of xanthelasma, the patient's age, and its greater degree of similarity with the previously reported cases of SGFP-JXG, favors the current diagnosis.

In conclusion, we report another rare case of SGFP-JXG occurred on the face of a 3-year-old boy. As shown in the previous reports, a subset of the lesion can persist for several years without resolution; hence persistent lesions may 

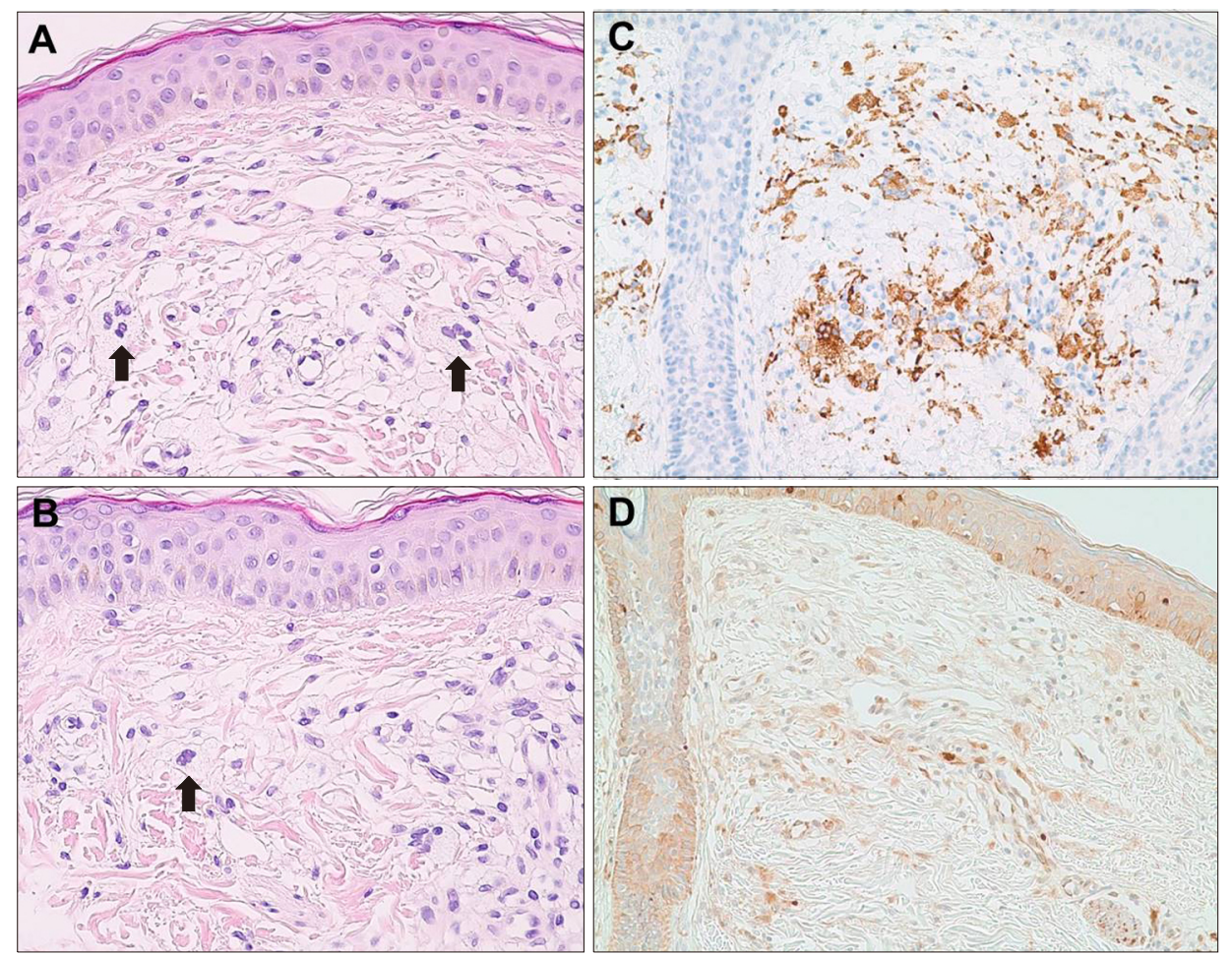

Fig. 2. (A, B) Haematoxylin-eosin staining of the yellowish plaque on the right cheek. Numerous foam cells and Touton giant cells with occasional foreign body giant cells are seen as indicated by arrows. (C) Immunohistochemical staining of the lesion showing CD68 positive histiocytes. (D) Immunohistochemical staining of the lesion showing a negative staining result on S-100 $(\times 20)$.

require an attempt for a treatment. A few previous DNPX cases, which have similar histologic features as our case, reported successful treatment outcomes with ablative lasers and dermabrasion ${ }^{11-13}$. Ablative lasers such as $\mathrm{CO}_{2}$ and Er:YAG lasers are safe and effective devices for the removal of epidermal or superficial dermal lesions. The current report attempted a single session of fractional ablative $\mathrm{CO}_{2}$ laser, which resulted in a significant regression in size of the lesion. To our knowledge, there is only one other case that attempted ablative $\mathrm{CO}_{2}$ laser on xanthogranulomas of the skin, and it reported some scarring left after the laser therapy ${ }^{14}$. The use of fractional laser in our case might have contributed to the avoidance of post-laser scarring, since limited ablation was induced at each microthermal zone, thus augmenting collagen remodeling with a decreased risk of scarring compared to fully ablative technology ${ }^{15}$. A long term follow-up after the treatment showed a continuous effect of the treatment. Hence, this is the first case report of a persistent SGFP-JXG on which a single fractional ablative laser therapy was performed with a promising outcome.

\section{CONFLICTS OF INTEREST}

The authors have nothing to disclose.

\section{ORCID}

Young In Lee, https://orcid.org/0000-0001-6831-7379

Sang Ho Oh, https://orcid.org/0000-0002-4477-1400

\section{REFERENCES}

1. Gunson TH, Birchall NM. Symmetrical giant facial plaquetype juvenile xanthogranuloma. J Am Acad Dermatol 2008; 59(2 Suppl 1):S56-S57.

2. Szczerkowska-Dobosz A, Kozicka D, Purzycka-Bohdan D, Biernat W, Stawczyk M, Nowicki R. Juvenile xanthogranuloma: a rare benign histiocytic disorder. Postepy Dermatol Alergol 2014;31:197-200.

3. Dehner LP. Juvenile xanthogranulomas in the first two decades of life: a clinicopathologic study of 174 cases with cutaneous and extracutaneous manifestations. Am J Surg Pathol 2003;27:579-593.

4. Sangüeza OP, Salmon JK, White CR Jr, Beckstead JH. Juvenile xanthogranuloma: a clinical, histopathologic and immunohistochemical study. J Cutan Pathol 1995;22:327-335.

5. Yazganoglu KD, Erdem Y, Buyukbabani N, Baykal C. A giant congenital plaque. Pediatr Dermatol 2012;29:217-218.

6. Sugiura K, Hasegawa $Y$, Shimoyama $Y$, Hashizume $H$, Akiyama M. Symmetrical giant facial plaque-type juvenile xanthogranuloma persisting beyond 10 years of age. Acta Derm Venereol 2014;94:465-466.

7. Miyagawa F, Fukumoto T, Kobayashi N, Asada H. Successful treatment of diffuse normolipemic plane xanthoma with probucol. Case Rep Dermatol 2013;5:148-151. 
8. Altman J, Winkelmann RK. Diffuse normolipemic plane xanthoma. Generalized xanthelasma. Arch Dermatol 1962; 85:633-640.

9. Oka M, Okamura A, Kawano S, Fukumoto T, Sakaguchi M, Nishigori C. Diffuse plane normolipemic xanthoma associated with chronic myelomonocytic leukemia-1. Eur J Dermatol 2014;24:112-113.

10. Vail JT Jr, Adler KR, Rothenberg J. Cutaneous xanthomas associated with chronic myelomonocytic leukemia. Arch Dermatol 1985;121:1318-1320.

11. Kim KJ, Lee DP, Suh HS, Lee MW, Choi JH, Moon KC, et al. Diffuse plane xanthoma in a patient with chronic myeloid leukemia. J Dermatol 2004;31:503-505.
12. Lorenz S, Hohenleutner S, Hohenleutner $U$, Landthaler $M$. Treatment of diffuse plane xanthoma of the face with the Erbium:YAG laser. Arch Dermatol 2001;137:1413-1415.

13. Bragg J. Diffuse plane xanthomata. Dermatol Online J 2005; $11: 4$.

14. Klemke CD, Held B, Dippel E, Goerdt S. Multiple juvenile xanthogranulomas successfully treated with $\mathrm{CO}$ laser. J Dtsch Dermatol Ges 2007;5:30-33.

15. Trelles MA, Leclère FM, Martínez-Carpio PA. Fractional carbon dioxide laser and acoustic-pressure ultrasound for transepidermal delivery of cosmeceuticals: a novel method of facial rejuvenation. Aesthetic Plast Surg 2013;37:965-972. 